\title{
Y el claustro se abrió al siglo: Pedro Zulen y el Boletín Bibliográfico de la Biblioteca de San Marcos (1923-1924)
}

\author{
Alberto Loza NeHMAD \\ Universidad Nacional Mayor de San Marcos
}

$\&$

\section{Resumen}

En 1923, Pedro Zulen (1898-1925) fundó el Boletín bibliográfico de la Biblioteca de la Universidad Nacional Mayor de San Marcos. La publicación del boletín fue resultado de la modernización de la biblioteca impulsada por el rector Manuel Vicente Villarán y conducida por Zulen quien publicó los quince números del primer volumen, que se cierra en 1924. En esos dos años volcó su talento intelectual y editorial en el boletín e hizo de él una publicación académica reconocida a nivel internacional. En esa tarea, él se desempeñó como el puente entre dos generaciones. Dirigió, sobre todo, a un grupo de estudiantes que había salido de la adolescencia durante el movimiento de la Reforma Universitaria. Ellos se consolidaron intelectualmente, como colectivo, en las tareas de la publicación del Boletín. Este grupo, de la Generación del Centenario, tuvo después un destacado papel en la vida intelectual peruana del siglo XX.

Palabras claves: Universidad Nacional Mayor de San Marcos, Biblioteca, Pedro Zulen, Bibliografía peruana, Boletín bibliográfico.

\section{Abstract}

In 1923 Pedro Zulen (1898-1925) founded the Library of San Marcos' Boletín Bibliográfico. The publication of this journal was the result of the modernization of the library stimulated by Rector Manuel Vicente Villarán and carried out by Zulen, who published the first volume of the Boletin Bibliográfico (15 issues, 1923-1924). In that period Zulen applied his editorial talents to this publication and turned it into an internationally acclaimed journal. In this endeavor he acted as an intergenerational link; most of all, 
he directed a group of students who had come of age during the university reform movement. While working for the Boletín Bibliográfico, they coalesced as a collective. They belonged to Generation of the Centennial (of Peru's independence) and later exerted a lasting influence on $20^{\text {th }}$ century Peruvian intellectual life.0

Key words: Universidad Nacional Mayor de San Marcos library, Pedro Zulen, Peruvian bibliography, Boletín Bibliográfico.

\section{Introducción}

La aparición en 1923 del Boletín Bibliográfico de la Biblioteca de la Universidad de San Marcos marca el inicio del género de las publicaciones bibliotecarias académicas en el Perú. Este artículo discute el contexto de ese inicio. Básicamente, propone que el primer volumen del Boletín sanmarquino -fundado y dirigido por Pedro Zulen- no solo fue el vocero de la modernización bibliotecaria en la Universidad de San Marcos, sino que se constituyó en un privilegiado portal de la modernidad universitaria y de las novedades intelectuales en la conservadora universidad limeña. El auspicio del rector Manuel Vicente Villarán a las labores de la Biblioteca, la visión editorial del bibliotecario Pedro Zulen, la participación en esta publicación de estudiantes identificados con el movimiento de la Reforma Universitaria así como de profesores abiertos a las novedades del siglo, son algunas de las razones que explican el destacado perfil del primer volumen del boletín de la biblioteca sanmarquina.

Antes de exponer las características generales del Boletín y el juicio que mereció de sus contemporáneos, se hace necesaria una visión somera acerca de la época en la que sale el Boletín Bibliográfico universitario, así como algunas referencias a dos publicaciones de índole bibliográfica que precedieron al boletín de la Universidad.

Ciertamente 1923 no es un año temprano en su siglo, pero el siglo XX ingresó algo tarde a la Universidad de San Marcos. Algunas fechas y datos nos pueden ayudar a tener una mejor perspectiva. Si bien desde mediados de la primera década habían aparecido en el Perú los primeros grupos obreros con discursos anarquistas, el viejo claustro tendría que esperar hasta 1919 para que el movimiento de la Reforma Universitaria buscara la renovación de la enseñanza, una universidad abierta a las 
nuevas realidades de la posguerra y mayores vínculos con la sociedad de su entorno, especialmente las nuevas clases obreras urbanas. Por otro lado, las prácticas bibliotecarias modernas eran aún recientes. Melvil Dewey había inventado su método de clasificación decimal en 1876 y contribuido a fundar la primera escuela de bibliotecarios en la Universidad de Columbia en 1887. Mientras, la Universidad de Lima se recuperaba lentamente de la Guerra del Pacífico (1979-1983) y su biblioteca, inaugurada en 1871, no reabriría sus puertas hasta 1904. En el Perú, el primer artículo acerca del método decimal había sido publicado por Federico Villarreal en 1910. (ver Villarreal: 190)

El boletín de la biblioteca de San Marcos no fue la primera publicación periódica dedicada exclusivamente a los libros o a las bibliotecas. Lo habían precedido el Boletín Bibliográfico: Órgano de la imprenta y librería de Carlos Prince, y publicación destinada a la inserción de toda clase de anuncios, y el Boletín de la Biblioteca Nacional, editado por primera vez bajo la dirección de Alejandro O. Deustua. El boletín de Carlos Prince se dedicaba al anuncio de las novedades bibliográficas en Lima y a la publicación de algunas reseñas, y el de la Biblioteca Nacional, a dar cuenta de la marcha de la primera biblioteca pública del país. El Boletín de la biblioteca universitaria, en el ámbito académico, cubriría también tareas similares. Con justicia, el boletín de la biblioteca de San Marcos incluyó en su cuarto número (octubre de 1923) un artículo sobre Carlos Prince y su obra bibliográfica, escrito por el educador y filólogo Enrique D. Tovar y Ramírez.

Carlos Prince (París, 1836 - Lima, 1919), tipógrafo, editor, aficionado a la historia y la filología americanas, pasó al Perú en 1862. Publicó su Boletín Bibliográfico entre enero de 1888 y julio de 1901. Era una publicación mensual con una tirada (según su editor) de cuatro mil ejemplares distribuidos gratuitamente. Este boletín era escrito, editado y financiado por Prince. ${ }^{1}$ El artículo sobre Carlos Prince publicado por el Boletín Bibliográfico de San Marcos aparece así como un debido homenaje a quien, entre varios y prolongados esfuerzos editoriales, por primera vez en el Perú fundó en 1888 una publicación exclusivamente dedicada al género bibliográfico. ${ }^{2}$

Por su parte, el Boletín de la Biblioteca Nacional, fue publicado por primera vez en enero de 1919, a poco de haber sido nombrado director 
de la biblioteca Alejandro O. Deustua. Impreso en un formato pequeño (22 x $16.5 \mathrm{~cm})$, este boletín cumplía con pulcritud las obligaciones de una publicación de su tipo. En su Memoria de 1919, el director de la Biblioteca Nacional informaba que el boletín de ésta contenía «los datos relativos a la comunicación oficial de este despacho, al archivo Paz Soldán, a los libros, folletos y revistas nacionales y extranjeras, a las obras ofrecidas en canje y solicitadas por esta Biblioteca y el movimiento estadístico mensual de lectores». Este boletín se hacía especialmente necesario, continuaba, debido a "la carencia de un catálogo» que orientara a los lectores.

\section{El Boletín Bibliográfico de la Biblioteca de San Marcos}

El Boletín Bibliográfico de la Biblioteca de la Universidad Mayor de San Marcos publicó su primer número en julio de 1923, tres meses después de que su editor fundador, Pedro Zulen, se hiciera cargo de la dirección de la biblioteca. Entre julio de 1923 y diciembre de 1924, estando en vida su fundador, se publicaron los quince números que hacen el primer volumen. La calidad de su contenido y diseño lo distinguieron desde un principio. El joven Jorge Basadre, en «La herencia de Zulen», artículo aparecido en el número de marzo de 1925, poco después de la muerte de Zulen, califica a esta publicación como «la mejor... de su género en América». ${ }^{3}$

Aunque escrito en el número de homenaje póstumo a Pedro Zulen, el entusiasta juicio de este joven estudiante de derecho no era una burbuja retórica. Jorge Basadre trabajaba en la Biblioteca Nacional cuando fue llamado por Zulen para que sirviera en el turno nocturno que la Biblioteca de San Marcos abrió en junio de 1924. Así, como estudiante y como empleado de bibliotecas, conocía desde dentro la magnitud de la renovación que había experimentado la biblioteca universitaria en el lapso de los dos años en que Zulen fue su director. En esos años la comunidad universitaria había pasado por un período de significativos cambios. Los impulsos modernizadores del rector Manuel Vicente Villarán (1922-1924) sintonizaron con las exigencias de renovación que desde 1919 habían venido levantando los estudiantes bajo el nombre de Reforma Universitaria. Uno de los logros 
de ese momento fue la modernización de la Biblioteca de San Marcos. Una empresa de rápida pero sólida gestación, el Boletín Bibliográfico no era sino el remate editorial de una renovación bibliotecaria que había sido concebida y llevada a cabo por Pedro Zulen, y propiciada desde la rectoría por Manuel Vicente Villarán. Tras la renuncia del rector en 1924 y la muerte del bibliotecario a inicios de 1925, se cierra este breve pero trascendente ciclo. «La herencia de Zulen» aparece entonces no solo como un homenaje sino también como un balance minucioso de la obra realizada.

En su artículo Basadre comienza refiriéndose a los trabajos en la biblioteca: "Y hay que comenzar por decirlo desde aquí mismo, sin temores porque es la verdad. Zulen no llenó su obra de bibliotecario. El catálogo no está concluido; la clasificación de los libros está por hacerse...». Era cierto, la muerte del bibliotecario de San Marcos ocasionó la casi interrupción de la catalogación cuando se había avanzado con poco más de la mitad de los libros, y tendría que esperarse 17 años para que se concluyera solo un catálogo de autores. Aunque breve en el tiempo, el impulso dado por el director había renovado significativamente las nociones existentes sobre catálogo, desarrollo de colecciones y servicios de la biblioteca; había además editado los quince números del primer volumen de una publicación de notable calidad (que continuaría siendo publicada hasta 1966) y, de manera importante, había contribuido al cimentamiento intelectual de algunos jóvenes universitarios pertenecientes a la llamada «Generación del Centenario». En el mencionado artículo Basadre escribía:

«El valor primordial de esta obra de Zulen llegó a ser sólo el de haber sabido suscitar. Trajo a su oficina, que vegetaba casi desapercibida, ese ritmo febril de los privilegiados centros de cultura, e hizo de ella no un centro burocrático sino un dinámico instrumento. Incrementó considerablemente los libros convirtiendo a la Biblioteca de la Universidad en la mejor del país en cuanto se refiere a la producción moderna...»

«Un dinámico instrumento» como lo opuesto a una rutinaria oficina burocrática: de esos recintos salió el Boletín Bibliográfico de la Biblioteca de San Marcos. 


\section{«El Boletín Bibliográfico... es órgano de la Biblioteca»}

El primer número del Boletín de San Marcos salió con ocho páginas, en un formato de tamaño ligeramente mayor $(17 \times 24 \mathrm{~cm})$ al de la Biblioteca Nacional y en dos columnas. El nombre Boletín Bibliográfico en fuente alta encabezaba la página a todo lo ancho; en la línea siguiente se podía leer la mención de responsabilidad que lo distinguiría en adelante: «Publicado por la Biblioteca de la Universidad Mayor de San Marcos». En la primera página, inmediatamente después del Sumario que abría la columna izquierda, venía una declaración de principios titulada «Propósitos»: «El Boletín... es órgano de la Biblioteca. Nos proponemos dar cuenta de su movimiento y cultivar en él las materias que guardan conexión con sus labores». Comunicaba en seguida que otra de las aspiraciones de la publicación era «aportar datos y medios que faciliten el trabajo del investigador». Finalmente, el Boletín expresaba su intención de resaltar los estudios de bibliografía peruana.

En el mencionado primer número del Boletín seguían a la declaración de propósitos dos artículos, uno de Pedro Zulen («Federico Villarreal, 1850-1923») y otro de Raúl Porras Barrenechea ("Contribuciones a la Bibliografía Peruana: José Antonio de Lavalle y Arias de Saavedra, 1833-1893»). Venía luego la sección «Movimiento de la Biblioteca», en la que se informaba de manera general sobre los procedimientos de catalogación iniciados en febrero de ese año y sobre las características del «diccionario-catálogo» que se empezaba a formar. El Boletín informaba a continuación sobre las adquisiciones recientes y las subscripciones vigentes. Cerraba el primer número una nota titulada «Nuestro Boletín»: «El Boletín Bibliográfico circula entre los profesores y alumnos de la Universidad Mayor de San Marcos, y se envía a las instituciones que lo soliciten. Todas las comunicaciones deben dirigirse a D. Pedro S. Zulen, Bibliotecario de la Universidad y editor del Boletín. Apartado 168, Lima, Perú, S[ud] A[mérica]». En el pie de imprenta se lee Sanmartí y Cía. Impresores.

Los siguientes números del primer volumen del Boletín mantuvieron básicamente el mismo formato aunque se fueron añadiendo secciones (de las que se tratará más adelante) y páginas. Hubo también 
modificaciones ligeras en la portada. El número conmemorativo del bicentenario de Kant ( $\mathrm{N}^{\circ}$ 8-9, mayo-junio, 1924) mostraba su retrato en la portada ocupando tres cuartos de página. Inmediatamente después, bajo el título «El bicentenario de Manuel Kant», comenzaba a dos columnas el primer artículo, dejando que el Sumario abriera la siguiente página. Los números 10-14 (julio-noviembre, 1924) y 15 (diciembre, 1925) mostraron el Sumario en toda la portada. En general, puede afirmarse que pese a la variación en las portadas, desde su primer número el Boletín adquirió una identidad física. Con respecto a la impresión del Boletín se observa que, salvo el número 15 que fue impreso en la Imprenta Garcilaso - Pileta de la Merced 156, los anteriores catorce lo fueron en la ya mencionada Sanmartí y Cía. Impresores. La Sala de Investigaciones Bibliográficas de la Biblioteca Central de San Marcos conserva un tomo que contiene los quince números (pp: 1265) del primer volumen, empastados en los talleres del encuadernador alemán Enrique J. Polick.

\section{El fundador del Boletín Bibliográfico}

El Boletín Bibliográfico nació fruto del impulso que movió la vida ciertamente febril de Zulen -persona de ideas, iniciativas y accionesdesde su regreso de los Estados Unidos. Apremiado por problemas de índole tanto económica como familiar, éste volvió al Perú en octubre de 1922 tras una estada de tres años en la Universidad de Harvard donde, además de filosofía y psicología, había estudiado lo que después se denominaría ciencias bibliotecarias. A principios de febrero de 1923, empieza las labores de catalogación de la biblioteca universitaria. El primero de mayo, asume las funciones de director de la biblioteca y en julio, nueve meses después de haber llegado al Perú, da a luz al primer número del Boletín. ¿Cuánto se pareció esta publicación a su editor fundador?

La trayectoria de Pedro Zulen es singular. Aunque murió como bibliotecario de San Marcos, editor del boletín de la Biblioteca y doctor en filosofía, su carrera no fue exclusivamente académica como tendió a serlo la de los demás miembros del grupo universitario conocido como la «Generación del Novecientos». A diferencia de muchos de sus 
pares generacionales, su doctorado no lo recibió al inicio de su carrera sino cuando ya había logrado una, a los treinta y cuatro años de edad. Más aún, empezó en 1906 como estudiante de la Facultad de Ciencias y terminó doctorándose en la de Filosofía en 1924. Estudió en la Universidad de Harvard cuando lo más frecuente era que los intelectuales peruanos -con excepciones como la de Julio C. Tellopasaran por la experiencia europea o que ansiaran hacerlo. Mientras, desde 1909, se dedicó al activismo político, hasta hace poco su faceta más conocida y recordada. ${ }^{5}$

Zulen se inició en grande en la vida pública en 1909 con su iniciativa de fundar una asociación de defensa indígena, tarea en la que participaron varios otros socios del Centro Universitario, incluido José de la Riva Agüiero. A diferencia de ellos, sin embargo, Zulen agregó a su agenda política el tema del centralismo limeño. Su trabajo en la Asociación Pro Indígena, empresa pragmática de defensa ciudadana, lo hizo en colaboración estrecha con un ingeniero, matemático y sociólogo de concepciones positivistas y militancia pierolista, Joaquín Capelo, y con una mujer autodidacta e independiente, Dora Mayer. El hecho de haber trabajado en este tipo de empresa colaborando con una mujer por el espacio de seis años, a pesar de todas las dificultades y complejidades de la relación que ambos mantuvieron, lo destaca en un medio y una época misóginos. ${ }^{6}$ Es esta original trayectoria la que José Carlos Mariátegui rescata cuando describe a Zulen, ya fallecido, como el «independiente» con más "personalidad y significación», en una generación sin bandos o bloques antagónicos significativos (1987: 293).

La producción escrita de Zulen fue también variada e independiente, como la vida de su autor. Aparte de sus tesis y de los artículos que escribió para el Boletín Bibliográfico, según la bibliografía elaborada por su hermana Esther, Zulen publicó poco más de un centenar de denuncias, informes y artículos relacionados con la Pro Indígena, una docena de poemas y más de sesenta artículos de divulgación sobre asuntos de ciencia, literatura, educación, así como algunos sobre espiritismo y las posibilidades de vida extraterrestre (Esther Zulen, 1925: 9-19). Su interés en temas como los dos últimos con seguridad acentuó los prejuicios contra un peruano de origen chino conocido por su tenaz campaña antigamonal. En enero de 1912, en respuesta a 
un entredicho periodístico sostenido con Zulen, una carta firmada por «La Redacción» de la Ilustración Peruana, enviada a la revista Variedades, terminaba expresando con burlón tono conmiserativo: «iPobre joven! Él no tiene la culpa de ciertas cosas, sino la Pro Indígena y el espiritismo» (Variedades $\mathrm{N}^{\circ}$ 201: 24). La inclusión de ambas referencias en la misma burla da una idea de los parámetros en los que se desenvolvía la medianía contemporánea.

La amplitud de las inquietudes de Zulen, expresada en la variedad de su obra periodística, no terminaba de amoldarse al estrecho mundo universitario limeño de entonces. Es preciso recordar que el movimiento de la Reforma Universitaria se había gestado hacía menos de un lustro. Al respecto, resulta ilustrativo revisar el balance sentido y leal pero a la vez franco que algunos amigos y colegas suyos hicieron sobre su obra. Los juicios de Jorge Basadre, Víctor Modesto Villavicencio y Luis Varela y Orbegoso (Clovis), aparecidos en el Boletín Bibliográfico en el número de homenaje póstumo a Zulen, son coincidentes: en términos de su producción, Zulen -afirman- no era un hombre de libros sino de artículos. Tras una lectura de su bibliografía esta observación nos resulta obvia; sin embargo, resulta interesante destejer las explicaciones que los mencionados ofrecen ante la ausencia de libros en la producción del fallecido bibliotecario.

Víctor Modesto Villavicencio contrapone la producción de libros a la de artículos. Según él, Zulen no habría desarrollado todo su potencial por lo absorbente que le habría resultado la publicación de artículos: «La obra de Zulen es dispersa. A veces el enemigo del talento es el diario. La tarea se hace difusa, ingrata, publicando estudios o artículos que durarán lo que dura una hoja de papel. Si Zulen hubiera dedicado su tiempo a la preparación de libros, su prestigio se habría formado violentamente» [subrayado mío] (1925: 8). Se percibe en estas palabras un tono de excusa por la ausencia de «libros» en la producción de Zulen, asociado con la idea del prestigio que otorga su publicación. Esta mención al prestigio debe entenderse en su tiempo y en su lugar. El talento y la altiva personalidad de Zulen por sí solos no le habrían bastado en San Marcos, al contrario; el rector Villarán impuso su nombramiento sobre el sentir de algunos profesores que lo objetaban por tratarse de "un chino» y por haber estado envuelto en el «escándalo» 
de Dora Mayer (Basadre, 1975: 246). Villavicencio, admirador del Zulen intelectual y bibliotecario, parecía no considerar necesariamente "prestigiosa» la actividad pro indígena o editorial de su mentor.

Luis Varela Orbegoso, al describir la producción de Zulen, ofrece una explicación de naturaleza más intelectual: «La multiplicidad de la vida presente, que impone al escritor una actividad extraordinaria, hacía de Zulen más un hombre de revistas, que un hombre de libros. Su espíritu se complacía en la novedad palpitante y así podía seguir al día el ondulante camino del pensamiento moderno» [subrayado mío]. ${ }^{15}$ Puede advertirse en las líneas escritas por Varela Orbegoso la percepción de un mundo moderno caracterizado por lo múltiple, lo acelerado y lo urgente; este mundo habría sido cabalmente leído por Zulen escritor. En efecto, a fines de la segunda década del siglo, cerrado el primer ciclo del movimiento reformista universitario, el siglo XX empezaba a infiltrar el claustro sanmarquino. Zulen fue un cabal lector de este fenómeno.

Un juicio más crítico y personal proviene de un Jorge Basadre a los veintidós años de su edad, la persona que más afectuosa y largamente continuaría luego escribiendo sobre Zulen:

\footnotetext{
«Quizá la síntesis, el esfuerzo creador, poderoso y sistemático le estaban vedados; acaso servía más para acumular y orientar que para producir [subrayado mío]. Pero sus artículos -y artículos largos son sus libros, que no reflejan por cierto su personalidad íntegra- tienen un valor subido. Allí está la prueba de su constante elaboración intelectual. Se ve a través de ellos su cultura, hecha por sí mismo; para todo hay que ser aún autodidacta en el Perú. Y se ve su juicio, igualmente hecho por sí mismo».16
}

Basadre, amigo y discípulo, expresa con dudas (quizás, acaso) su descripción de las calidades intelectuales de Zulen. Sin embargo, más que establecer una oposición entre libros y artículos, Basadre se sumerge más y sondea las diferencias entre "producir» y «acumular y orientar» los conocimientos; esto es, se pregunta por ubicar los talentos de Zulen en lo que podríamos describir como algunos lugares de la «economía política» de la producción intelectual: la producción, la distribución de los conocimientos. Este juicio, que se refiere en última instancia al papel de Zulen como intelectual, propone que éste quizá estaba constituido más para lo último, juicio que nos retrotrae al anteriormente 
citado elogio de Basadre: «haber sabido suscitar»; esto es, el mérito de un maestro y el de un bibliotecario. ${ }^{7}$ Precisamente a esto se refería Basadre años después al escribir sus memorias: «Confieso que en él me inspiré en muchas ocasiones de mi vida. No me enseñó en el aula; pero me enseñó con el ejemplo y a través de innumerables y sencillas charlas en la biblioteca y en las calles». (1975: 247) Estas palabras siempre invitan a salir de los campus universitarios para apreciar mejor el panorama.

Falta añadir otro aspecto para presentar una visión más completa de Zulen: las dimensiones espirituales de su personalidad. Conociendo su trayectoria política y su vocación por el activismo intelectual, resulta invitador intentar ver en el Boletín Bibliográfico una asociación entre lo espiritual y lo político. Esto, teniendo en cuenta que en sus memorias Basadre refiere que Zulen repetidamente le había manifestado su decisión de contribuir a la "renovación espiritual» del Perú desde su puesto en la biblioteca, dado que su precario estado de salud le impedía otro tipo de militancia. (Basadre, 1975: 247) Esta militancia académica y espiritual ya la había dejado entrever Zulen en 1919 en el remate que daba a su artículo periodístico «Harvard y San Marcos» (La Prensa, 20 de agosto, 1919):

«iCómo el espíritu de verdad y justicia que emerge de las páginas vibrantes
del discurso [de Manuel Vicente Villarán (1900)] sobre 'Las profesiones
liberales en el Perú' y del opúsculo sobre 'El problema de la educación
moral', arrasara de una vez con ese concepto muy peruano de que la
Universidad es un conjunto de empleos que deben distribuirse entre
parientes y amigos... iEspiritualicemos San Marcos!»

En esa mención a la obra de su maestro, amigo y protector Villarán, y en su llamada final, escritas en los meses en que Zulen terminaba de escribir La filosofía de lo inexpresable (Tesis de bachillerato, Lima: Sanmartí y Cía., 1920), aparece el mismo impulso idealista que habría de comunicar menos de un lustro después a Basadre, cuando éste trabajaba para el servicio nocturno de la biblioteca de San Marcos. No resulta entonces aventurado sostener que en la misión renovadora que se había propuesto, el Boletín Bibliográfico habría sido concebido como el instrumento -o la herramienta, tales son los significados de «órgano» tanto en latín como en griego- con el que quería llegar a un público más numeroso. 
Leídos desde nuestro presente, los juicios anteriores coinciden en describir no sólo a un maestro y a un bibliotecario sino también a un editor de talento, que lo fue sin duda. No sorprende que quienes los pronunciaron, universitarios del primer lustro de los años veinte (Amauta salió recién en la primavera de 1926), se sintieran en la necesidad de mencionar la oposición entre escribir artículos y escribir libros. Pareciera que al desplazarse por la universidad limeña de entonces lo hicieran con la ayuda de una linterna capaz solamente de detectar libros pero miope ante otras formas de la producción cultural. En las épocas de acelerados cambios sociales y culturales no son los libros sino las revistas las que informan sobre lo nuevo. Sobre el modo de informar sobre ese mundo múltiple, acelerado y cambiante apuntaba, contra-académico, José Carlos Mariátegui: «el mejor método para explicar y traducir nuestro tiempo es un poco periodístico y un poco cinematográfico». ${ }^{8}$ El valor del Boletín Bibliográfico nació así, también, de la capacidad de su editor Zulen para interpretar los lenguajes y las sensibilidades cambiantes de su tiempo.

\section{El Boletín Bibliográfico, Vol. I, 1923-1924}

La labor de Pedro Zulen en el Boletín no podría comprenderse a cabalidad sin tener en cuenta sus vínculos con el rector Villarán ni la política de reformas que este último intentó poner en marcha desde el rectorado entre 1922 y 1924, luego del movimiento estudiantil de la Reforma Universitaria de 1919. Ambos personajes se habían conocido en 1912; entonces, Zulen trabajaba en la biblioteca universitaria mientras Villarán se desempeñaba como inspector de ésta. Se trató de un caso de mutua simpatía y admiración. Si la inteligencia del joven ayudante había llamado la atención de Villarán, el capitalismo progresista de éste contenido en su discurso contra la empleocracia y la profusión de profesionales liberales en el Perú, había hallado rápidamente un lugar en el socialismo parlamentarista de Zulen. En temas educacionales, además, ambos coincidían en su admiración por los sistemas educativo y universitario norteamericanos. Finalmente, esas afinidades confluyeron en el proyecto común de renovar la biblioteca, iniciado en 1922 luego de que Villarán fuera elegido rector y cuando Zulen aún permanecía en Harvard. Entonces, ellos empezaron a intercambiar planes e ideas. ${ }^{9}$ 
La elección de Villarán había dado fin a un receso universitario decretado en 1921, debido a un desencuentro entre el régimen leguiísta y los profesores civilistas de San Marcos. Entretanto, los estudiantes que irían a participar en el proyecto de Zulen, dirigentes de la Reforma Universitaria, carecían de un canal de expresión oficial en la Universidad. En 1922, la elección del nuevo rector despertó el optimismo entre ellos. En Mayo de 1922, en un artículo escrito para la revista Mundial, Luis Alberto Sánchez saludaba con exaltación la elección del nuevo rector: «Nunca, más que ahora, los elementos profesoral y estudiantil han marchado más de acuerdo. Jamás se ha presenciado solidaridad mayor que la que ahora ofrecen alumnos y catedráticos». ${ }^{10}$ Aunque el entusiasmo de la comunidad estudiantil fue disminuyendo conforme los acontecimientos políticos desbordaron las posibilidades e intenciones del rector hasta provocar su renuncia en 1924, la solidez de la dirección de Zulen en la Biblioteca y en el Boletín le aseguraron a esta publicación un prestigio que se cimentó muy rápidamente.

En esos primeros dos años el Boletín se hizo conocido por la inclusión de artículos de estudiantes destacados a la vez que de profesores reconocidos; a la amplia gama de temas tratados en los artículos publicados; a la inclusión de secciones que al mismo tiempo que daban cuenta de los acontecimientos de la universidad de San Marcos y su biblioteca, informaban también sobre universidades y bibliotecas del resto de América, Europa y Asia; y a la actividad de distribución y difusión del Boletín por el mismo Zulen y los estudiantes más comprometidos con las tareas de renovación bibliotecaria emprendidas. En suma, puede afirmarse que el Boletín bajo la dirección de Pedro Zulen expresaba un proyecto colectivo universitario. ${ }^{11}$

En esta publicación, desde los primeros números destacó la presencia de artículos escritos por un grupo de estudiantes vivamente interesados en una nueva visión de la historia del Perú. Estos estudiantes ya habían participado organizadamente en el Conversatorio Universitario y en la catalogación de la sección de «Papeles varios» de la Biblioteca Nacional: Jorge Guillermo Leguía, Raúl Porras Barrenechea, Luis Alberto Sánchez y Jorge Basadre. ${ }^{12}$ Nacidos entre 1897 y 1903, pertenecieron a la llamada "Generación del Centenario" (de la independencia peruana) y participaron activamente en los Comités de 
Reforma del movimiento de reforma universitaria de 1919. No se trataba, por tanto, de un grupo bisoño ni improvisado; además, Sánchez y Basadre ya trabajaban en la Biblioteca Nacional. Así, su presencia como colaboradores del Boletín constituía así un esfuerzo colectivo que fue públicamente reconocido como tal desde sus primeros momentos.

En octubre de 1923, cuando el Boletín acababa de publicar su cuarto número, un artículo de Clovis (seudónimo del historiador, diplomático y periodista Luis Varela Orbegoso) en su columna «La hora actual», del diario El Comercio (23 de octubre de 1923, edición de la tarde) lo calificaba como una publicación de "gran valor y mérito». Señalaba además que este boletín, «al mismo tiempo que trabajos de Zulen y de los catedráticos [Pedro] Dulanto [y Mariano] Iberico Rodríguez, publica artículos de jóvenes universitarios, como Leguía, Porras Barrenechea, Basadre, que son valiosas contribuciones al estudio de la literatura». El artículo no mencionaba a Luis Alberto Sánchez, quien acababa de regresar de un viaje de medio año que lo había llevado hasta Panamá. Sánchez, sin embargo, pronto sumó al de sus compañeros un breve escrito suyo sobre la curiosidad bibliográfica Miscelánea Austral de Diego Dávalos y Figueroa, el mismo que apareció en el № 7 (abril de 1924). Para entonces Porras ya había publicado tres artículos en el Boletín, Jorge Guillermo Leguía dos y Basadre uno. El número de artículos publicados, por supuesto, no es más que un dato. En su homenaje a Zulen, "Se nos ha ido un maestro», escrito bajo la forma de una carta a Basadre, Sánchez evoca la imagen de una colaboración más cotidiana, más personal en las tareas bibliotecarias: "Yo le he visto, lo hemos visto, Jorge, dar datos y orientaciones a historiadores, sin ser historiador; enseñarnos a hacer catalogación, cosa muy diferente de la bibliografía, y derrochar sus energías, sus últimas energías en llevar a cabo tal labor en la Universidad de San Marcos». (1925: 26)

Además de estos estudiantes, colaboraron con artículos para el primer volumen del Boletín algunos pares generacionales de Zulen, como el filósofo Mariano Iberico (1892-1974), el poeta y editor Enrique Bustamante y Ballivián (1883-1937), el jurista y catedrático de historia Pedro Dulanto (1889-1952), el educador y filólogo Enrique D. Tovar y R. (1888-1947), el jurista Pedro R. Samillán Carranza, también abogado 
de clientela china. ${ }^{13}$ Es posible relacionar a algunos de ellos con particulares vetas de intereses comunes con el editor. Con respecto a la filosofía destaca la presencia de Iberico, catedrático de Historia de la Filosofía Moderna en San Marcos, quien escribió sendos artículos conmemorativos sobre Pascal ( $\mathrm{N}^{\circ} 2-3$, agosto-setiembre, 1923) y Kant (No 8-9, mayo-junio, 1924). En ambas ocasiones Zulen también escribió lo suyo: «Don Quijote en Salamanca», una erudita y festiva semblanza de Miguel de Unamuno en la que reseñaba un artículo de éste sobre Pascal -«La foi pascalienne»- que Zulen acababa de leer en la Revue de Métaphysique et de Morale (París, № 2, 1923); y, «La modernidad de Kant», donde entre otros temas hace el seguimiento del pensamiento neokantiano en la filosofía de habla inglesa representada por los pragmatistas William James (1842-1910) y Charles Peirce (1838-1914), filósofos -y psicólogo además, James- norteamericanos.

La poesía ocupó un singular lugar entre los intereses de Pedro Zulen y éste le dedicó un memorable número del Boletín. En colaboración con Enrique Bustamante y Ballivián dio cabida en el No 15 (Dic. 1924) a numerosos poemas de José María Eguren, viejo amigo de ambos y por entonces una figura de creciente aunque reciente prestigio en la poesía hispanoamericana. ${ }^{14}$ Se trata de un número especial no sólo por el acierto de publicar una obra que al tiempo de hacerse cada vez más reconocida, se hacía menos disponible, sino también por ser el último número editado por Zulen. Fueron seleccionados para su publicación los poemas del libro Simbólicas (1911), algunos de La canción de las figuras (1916) y otros del entonces inédito Sombra. Estos poemas estuvieron acompañados de una reseña sobre Eguren escrita por Bustamante y Ballivián. La publicación de estos poemas, escribía éste, había sido considerada como "un deber bibliográfico» por hallarse agotados los mencionados libros en un momento en el que la atención de la crítica empezaba a enfocarse sobre la producción de Eguren. Abría la selección mencionada una foto del poeta con la dedicatoria «A Pedro S. Zulen, con grande admiración y sincero cariño». Las siguientes líneas de Bustamante y Ballivián destacan algunos nombres de la bohemia literaria que frecuentaba Zulen a principios de siglo y su relación con Eguren: 
«El medio nuestro estaba en esa época en un atraso absoluto. El romanticismo dominaba por completo y hasta los más tímidos ensayos modernistas eran recibidos con burla. Quienes conocían los versos de Eguren, creían que sólo habían de tener por comentario la risa. Y parece que estaban en lo cierto. Fué en 1908, que, primero, por su amistad con Enrique Bustamante y Ballivián, y, después, con Julio A. Hernández, Pedro S. Zulen y Abraham Valdelomar, [Eguren] comenzó a ser conocido en los círculos literarios...». (1924: 224)

Estuardo Núñez ha escrito que la publicación de los poemas de Eguren en el boletín de la Biblioteca de San Marcos significó su "consagración universitaria», cuando sus obras, antes desoídas, dada su escasez se consideraban ya joyas bibliográficas. Este número del Boletín, continúa Núñez, "se agotó prontamente». ${ }^{15}$ Profesores e intelectuales peruanos de generaciones mayores también contribuyeron al Boletín, como en los casos del jurista y político Francisco Mostajo (1874-1954), antes corresponsal de la Pro Indígena y colaborador del diario La Autonomía, diario fundado y dirigido por Zulen en 1915; de Carlos Wiesse (1859-1945), maestro de varias generaciones de historiadores; del doctor Emilio Sequi (1844-1925), activo puente entre las culturas peruana e italiana y él mismo fundador del semanario $L a$ Voce d'Italia en 1886; y Rómulo Cúneo Vidal (1836-1931), escritor tacneño conocido como Juan Pagador.

Como grupo, sin embargo, destaca la presencia de Jorge Guillermo Leguía, Basadre, Sánchez y Porras, quienes contribuyeron a que en su primer volumen el Boletín ofreciese una nueva perspectiva del siglo XIX peruano. Desde su participación en el Conversatorio Universitario (1919), estos estudiantes, bajo la influencia de Carlos Wiesse y José de la Riva-Agüero, se habían propuesto -escribe Luis Alberto Sánchez«estudiar al margen de todo criterio tradicional, los orígenes y el desarrollo del movimiento emancipador del y en el Perú» (1987: 130). Fruto de estas maduradas inquietudes son las pioneras contribuciones de Jorge Guillermo Leguía a la "historia doctrinaria» de la independencia y la república, así como el importante artículo histórico bibliográfico escrito por Basadre sobre el entonces inédito Peregrinaciones de una paría, de Flora Tristán. ${ }^{16}$ Las páginas del Boletín, abiertas críticamente a la historia, deben leerse también a la luz de las propias inquietudes históricas de su editor, de tono bastante radical ellas mismas. En 1918, 
por ejemplo, al calor de su campaña por una diputación suplente, Zulen había afirmado: «Hace más de un tercio de siglo que la derrota dio al traste con toda nuestra consistencia de país, y puso delante de nuestros ojos el camino regenerador. La guerra del 79 hizo darnos cuenta de lo ficticio y lo informe de nuestra nacionalidad». ${ }^{17} \mathrm{Al}$ pronunciarse de tal manera, más allá del tono que imponen los discursos de campaña, Zulen se situaba como peruano de una generación formada bajo la figura de Manuel González Prada.

Mientras en el plano local la actualidad de la «República Aristocrática» impelía a la investigación crítica del siglo XIX peruano, a nivel internacional la expectante e insegura paz de la posguerra terminaba de abrir el siglo XX con interrogantes que también fueron abordadas en algunas páginas del Boletín. Éste publicó reseñas sobre personajes de actualidad como el filósofo alemán Oswald Spengler, entonces visto con suspicacia entre los victoriosos aliados de 1919; Marcel Proust, reconocido por acercar la novela a la introspección psicológica; el profeta de la paz Mahatma Gandhi, visto por Romain Rolland. Con el mismo espíritu se tradujo una reseña sobre el fisiólogo y filósofo neokantiano Nicolai y su condena de la guerra y del nacionalismo. Las celebraciones de Pascal y Kant, por ejemplo, dieron oportunidad a que Zulen reseñara -como ya se apuntó líneas arriba- lecturas recientes de la obra de filósofos como Unamuno y William James.

El contenido del Boletín fue enriquecido con la inclusión de las secciones noticiosas «Crónica del Claustro» $\mathrm{y}$ «Ecos». La primera estaba dedicada a noticias del campus universitario y la segunda a acontecimientos estudiantiles, académicos y bibliotecarios de carácter internacional. La mención en estas secciones a grupos estudiantiles, a congresos académicos y a autoridades e instituciones universitarias, tanto nacionales como extranjeras, puede ser leída como el reflejo editorial de la noción de comunidad académica propugnada por Zulen: la universidad concebida como centro de investigaciones desde donde pueda seguirse «el movimiento de ideas que agitan hoy al mundo» y basada en prácticas educativas como los seminarios, en hábitos y costumbres ("un conjunto de reglas no escritas») opuestas a la política del favor, y en excelentes bibliotecas «donde se hallen todos los medios de investigación». ${ }^{18}$ Zulen en más de una ocasión contrapuso 
abiertamente esta propuesta comunidad supranacional y meritocrática de académicos a la universidad limeña estamental, vertical y provinciana.

La sección «Crónica del claustro», dedicada a San Marcos, empezó a salir en el número 2-3 y en adelante faltó solo en los números 5 y 15. Abundan en esta sección las referencias a conferencias, viajes, nombramientos y fallecimientos de profesores. El reportaje de lo académico cotidiano haciendo uso de un lenguaje de corte periodístico significaba ya una propuesta de redefinición de la comunidad universitaria limeña, pues legitimaba de hecho la participación estudiantil aun tan solo dejando testimonio de su presencia como público entusiasta de las conferencias. Una nota, a propósito de una serie de conferencias organizadas por la rectoría, nos presenta los perfiles y los límites de la topografía social y académica de entonces: «Terminada la conferencia, la juventud tributó al Dr. Iberico, una excepcional manifestación de simpatía, acompañándole hasta las puertas del Club Nacional». ${ }^{19}$

La sección «Ecos» estaba dedicada a noticias internacionales. A diferencia de la "Crónica del Claustro», los materiales que incluía tenían un tono más polémico aunque siempre ciñéndose a la arena universitaria. Contra el confinamiento de Unamuno decretado por Primo de Rivera se lee, por ejemplo, «La persecución contra Unamuno tiene un carácter típicamente inquisitorial. Unamuno no es específicamente un político. El directorio español no reprime, por tanto, la actividad faccionaria de un caudillo sino la actividad intelectual de un pensador y un maestro» [subrayado mío]. En la ciudadanía universitaria transnacional concebida por Zulen, cabían no sólo los profesores eminentes como Unamuno sino también los anónimos estudiantes rusos apátridas emigrados después de la revolución bolchevique: «...unos trabajan como obreros, otros sirven empleos modestos, unos perecen de hambre y los que pueden siguen sus estudios universitarios ${ }^{20}$. También se trataba sobre universidades y sus instituciones, como las bibliotecas del Japón, destruidas por un maremoto:

«Uno de los daños más grandes del maremoto del año pasado fue la completa destrucción de las bibliotecas. Bajo las llamas desaparecieron no sólo las de Tokio sino las de Nippon y Meiji, con cerca de dos 
millones de volúmenes en total. Solamente la Biblioteca de la Universidad Imperial de Tokio contenía 740,000 volúmenes». ${ }^{21}$

La inclusión de tales estudiantes y de regiones como el extremo Oriente, lugar antes reservado a lo exótico, sólo puede entenderse a cabalidad al leer de manera yuxtapuesta estas notas contra el fondo que provee la historia personal (orígenes étnicos, activismo político y universitario, curiosidad intelectual) del bibliotecario de San Marcos.

El primer volumen del Boletín permite imaginar a algunos de los representantes de la Generación del Centenario -todos ellos orientados entonces a la historia, pupilos de Carlos Wiesse y Riva-Aguiero y con las experiencias comunes de la amistad, las tareas del Conversatorio Universitario, la Reforma Universitaria y su trabajo en la Biblioteca Nacional- reunidos en torno al bibliotecario, quien bajo el concepto de «Misión preferente de la Biblioteca» (Basadre, 1925: 3), encarnaba la propuesta más avanzada y concreta de renovación académica en San Marcos. De manera muy concreta, estos estudiantes colaboraron estrechamente con la difusión internacional del Boletín, una tarea que da cuenta de un compromiso personal con las tareas de la Biblioteca.

Sobre la difusión misma puede decirse que fue asumida a cabalidad por los colaboradores más cercanos, además del director. En carta que a Zulen dirigió Rafael Heliodoro Valle, funcionario del Departamento de Bibliotecas de la Secretaría de Educación Pública de México, se advierte que Porras y Leguía habían enviado regularmente ejemplares del Boletín a dicho país: "Gracias a la deferencia de nuestros amigos Porras Barrenechea y Jorge Guillermo Leguía, he estado recibiendo con puntualidad el 'Boletín Bibliográfico' que usted dignamente dirige... créame que la visita de su revista en canje con nuestra publicación 'El libro y el pueblo' será siempre motivo de regocijo». Cartas como la anterior fueron publicadas en algunos diarios limeños. Entre ellas se tiene la de felicitación y agradecimiento por el Boletín enviadas por el historiador español Rafael Altamira; el jurista Ariosto D. González, ex director de la revista «Proteo» y el poeta C. Sarbat Ercasty, ambos uruguayos; el antropólogo e indigenista chileno Tomás Guevara, a quien Zulen había enviado libros peruanos en anteriores oportunidades; el escritor colombiano Gustavo Arboleda. ${ }^{22}$ 
Esta suerte de "participación total» de un grupo destacado de estudiantes en el proyecto de Zulen hace del Boletín una publicación con muchos textos mutuamente referenciales. Un ejemplo de ello lo dan Luis Alberto Sánchez y su artículo sobre el ya mencionado libro Miscelánea Austral. Se trataba de un libro que Sánchez no había podido consultar cuando escribía Los poetas de la colonia (Lima, 1921). Finalmente pudo hacerlo en Quito, en su viaje de 1923, en la biblioteca del erudito arqueólogo ecuatoriano Jacinto Jijón y Caamaño. Fruto de su encuentro con este raro ejemplar bibliográfico fue el artículo «Diego Dávalos y Figueroa» publicado en el $N^{\circ} 7$ de abril de 1924. Paralelamente, en la sección internacional «Ecos» del mismo número aparece una nota dando cuenta de la prisión del mencionado estudioso ecuatoriano: «Según nuestros informes, el señor don Jacinto Jijón y Caamaño... ha sido puesto en prisión por el Gobierno de su país. Se da como causa de ella razones de orden político. Deseamos su pronta libertad». Definitivamente, no se trataba de una publicación burocrática.

Su sólido prestigio convirtió al Boletín en un útil instrumento para otros fines de la Biblioteca aparte del de publicidad de novedades bibliotecarias. Con seguridad no fue una iniciativa sin estímulo previo la que empujó a los deudos del matemático Miguel Garaycochea a que donaran los manuscritos del Cálculo Binomial a la Universidad de San Marcos. En el primer número del Boletín, salido en Julio de 1923, la curiosidad bibliográfica así como el celo académico de Zulen habían hecho de la necrología de Federico Villarreal una reseña crítica sobre su obra y la de sus predecesores, entre ellos Miguel Garaycochea y su ya mencionado libro. Es significativo que mediante carta al rector fechada el 28 de noviembre de ese mismo año, Juan M. Garaycochea donara los manuscritos de su padre a los archivos de la universidad.

Para concluir volvemos a la pregunta anterior: ¿Se pareció el Boletín a su fundador? Ciertamente que sí. En él podemos ver las marcas de la carrera humana e intelectual de Zulen. Del mismo modo, tal como su fundador, el Boletín vino a cumplir el papel de intermediador entre dos épocas: aquella que vivió el Perú después de la Guerra del Pacífico y la que empezó a perfilarse durante el Oncenio y que descubrieron y describieron con maestría después Jorge Guillermo Leguía, Porras, Basadre, Sánchez y que constituye el siglo XX tal como lo conocemos. 
Desde las páginas del Boletín podemos ver con comodidad, como lo hizo su director, tanto el siglo XIX como el Perú moderno. ¿Quién otro convertiría la necrología de su ex decano Villarreal en una reseña sobre la producción matemática peruana del siglo XIX? ¿Quién más reuniría a Pascal y a Unamuno en un artículo para luego criticar en Primo de Rivera las bases de la futura dictadura franquista?

La muerte de Zulen dispersó al grupo que se organizaba para producirlo. Al escribir la necrología de su maestro, Sánchez escribía, fatídico: «Publicó el Boletín Bibliográfico, labor inconmensurable y nueva en el Perú, un Boletín lleno de sugestiones y perspectivas, con muchos datos concretos y muchos nuevos puntos de vista. Ya se truncará esa publicación, puesta en manos de Dios sabe que otro hombre». (Basadre, 1925: 26) (Es preciso recordar que el Boletín Bibliográfico continuó siendo publicado hasta 1966). Basadre, por su parte, renunció a la biblioteca de San Marcos "por un principio de dignidad al constatar que su obra quedaba detenida o desviada». (1975:194) Años después escribiría en su Historia de la República, refiriéndose a Pedro Zulen: «...en él pienso siempre con amor y esperanza». (1964: 4459)

En conclusión, esta revisión somera nos permite observar, en primer lugar, que en la Biblioteca y en el Boletín, Zulen continuó plasmando los principios y las características personales que volcó en su primera obra política. Lo particular de su labor en el Boletín de San Marcos consistió en su capacidad de hacer de éste una publicación que sirvió de puente entre generaciones dispuestas a ver y a mostrar el siglo XX a sus lectores. Con respecto al grupo de estudiantes que colaboró con él, por lo colectivo de su compromiso, por la importancia del Boletín para su propia formación intelectual, bien se les podría denominar la Generación del Boletín Bibliográfico.

\section{Notas}

Carlos Prince escribió una elocuente descripción de su vida y trabajos en Lima, véase: Prince 1913. Carlos E. Tovar R., menciona veintiún obras publicadas y catorce inéditas en la bibliografía de Prince; como colaboradores del Boletín Bibliográfico de Prince nombra a Manuel Atanasio Fuentes (El Murciélago), Federico Flores Galindo (Dalmiro), Domingo Martínez Luján, Eugenio Iturrino, al poeta ecuatoriano Nicolás Augusto González y al periodista español Eloy Perillán y Buxó. Véase Tovar y Ramírez, 1923: 27. 


\section{AlBeRTo LOZA}

2 La Biblioteca Central Pedro Zulen de la Universidad de San Marcos posee un volumen que contiene, encuadernados, los primeros 24 números del Boletín de Carlos Prince $(31$ x 22 cm, 258 pp., $1^{\circ}$. Ene. $1888-1^{\circ}$ Dic. 1889) impreso en la Imprenta del Universo, de su propiedad.

3 Basadre 1925: 2. Este ensayo fue reproducido, con ligeras modificaciones, como «Zulen» en Basadre 1928.

4 UNMSM, BIBLIOTECA 1940: 251-254. Agradezco al bibliotecario y estudiante del posgrado de historia de San Marcos, Antonio Cajas, por sus precisiones sobre este punto.

5 En Mayo de 2002 la Biblioteca Central de la UNMSM organizó la exposición Pedro Zulen, San Marcos y su tiempo. Las investigaciones realizadas con ese motivo contribuyeron a iniciar el rescate de la faceta de Zulen bibliotecario y a enriquecer la cronología de la bibliotecología en el Perú.

6 Resulta interesante advertir la ausencia del adjetivo «viril» en los escritos de Zulen que he podido revisar, en una época en la que parecía omnipresente. Basadre, por ejemplo, encomiásticamente calificaba Peregrinaciones de una paria como un "panfleto viril». Véase Basadre, 1923: 14

7 La imagen de Zulen como iniciador de la bibliotecología moderna en el Perú resulta fortalecida cuando se aprecia sus cualidades profesionales en el marco de lo mencionado como «Misiones de la Biblioteca Pública», en el Manifiesto de la IFLA/UNESCO sobre la biblioteca pública, 1994.

8 Citado en Beigel, 1998: 74.

9 Sobre la amistad y admiración mutua y la protección de Villarán (véase Basadre 1925: 3) y las páginas que dedica a Zulen en Basadre (1975: 177-264). Considérese la pregunta de Villavicencio: «Pero cabe una pregunta: sin Villarán ¿Zulen habría sido bibliotecario de la Universidad?», en Villavicencio 1925: 8. Sobre ideas educativas de Villarán y Zulen, véase Villarán 1900 y Zulen 1919. Sobre las decisiones para catalogar y renovar la biblioteca, agradezco a los investigadores María Moscoso Carbajal y Miguel del Castillo por proporcionarme transcripciones de las cartas de Villarán a Zulen (Lima, 15-VII-1922 y 18-I-1923) y la de Zulen a Villarán de (Harvard, 22-l-1923) del Archivo Zulen, de la Biblioteca Nacional del Perú.

10 Sánchez 1922b: 2. Sánchez describe a Villarán de manera admirativa («Prestigios de hombre y de maestro, de abogado estupendo y de político sin mácula y sin... política») en Sánchez, 1922b: 2.

11 Fernanda Beigel discute la noción de «Proyecto colectivo» en su artículo, Beigel 1998.

12 Sobre la tendencia «historicista» en la generación del Conversatorio y la Reforma Universitaria, véase Sánchez, 1987, t. 1: 130-131.

13 Comunicación personal de Fernando Samillán, de cuyos padres fue amigo y tocayo el erudito Pedro Samillán.

14 En 1920 el crítico norteamericano Isaac Goldberg dedicó un breve capítulo de su libro a Eguren. Los otros trataban de Darío, Rodó, Chocano y Blanco-Fombona. Véase Goldberg, 1920: 296-306.

15 Núñez pról. 1961: 17. Sobre lo mismo, en el Boletín Bibliográfico, Bustamante y Ballivián comienza su artículo afirmando «Agotadas las ediciones de 'Simbólicas', 1911, y 'La canción de las figuras', 1916...», véase Bustamante y Ballivián, 1924: 223.

16 Según J. G. Leguía, hay tres «momentos» importantes en la historia doctrinaria peruana del siglo XIX: los debates entre monarquistas y republicanos después de la independencia; entre liberales y conservadores a mediados de siglo; y el momento encarnada por González Prada, después de la Guerra del Pacífico. Leguía 1939: 63. Basadre se refiere a este enfoque como la «historia civil», en oposición a la historia de los personajes militares y sus batallas; véase Basadre 1939: 9-10. 
17 La Evolución. Publicación diaria (Huancayo, 1918): 1. Agradezco a Narda Henríquez Ayín por facilitarme una fotocopia de ese diario.

18 Véase Zulen 1919; y la carta que envió al presidente de la Federación de Estudiantes del Perú agradeciéndole por el voto de simpatía recibido, El Comercio (Lima), 19 de junio de 1924, edición de la mañana.

19 UNMSM. Biblioteca (1923): 20

$20 \quad$ UNMSM. Biblioteca (1924a): 30

21 UNMSM. Biblioteca (1924b): 107

22 En la Sala de Investigaciones Bibliográficas de la Biblioteca Central de la UNMSM se guarda un álbum encuadernado con el título grabado en su tapa: «Recortes de Periódicos». Es un cuaderno de cuentas en cuyas primeras 14 páginas están pegadas 28 notas publicadas relativas a la Biblioteca sanmarquina, entre el 15 de septiembre de 1923 y el 5 de enero de 1925.

\section{Referencias bibliográficas}

BASADRE, Jorge (1923): «Al margen de un libro olvidado: Flora Tristán en el Perú». Boletín Bibliográfico publicado por la Biblioteca de la Universidad de San Marcos, 1 (2-3); pp. 11-14.

(1925): «La herencia de Zulen». Boletín Bibliográfico publicado por la Biblioteca de la Universidad de San Marcos, 2 (1); pp. 2-6.

(1928): Equivocaciones: Ensayos sobre literatura penúltima. La Opinión Nacional, Lima.

pról. (1939): Estudios Históricos. Ercilla, Santiago de Chile, pp. 9-13.

(1975): La Vida y la Historia: ensayos sobre personas, lugares y problemas. Fondo del Libro, Banco Industrial del Perú, Lima.

(1964): Historia de la República del Perú. 5a. ed., t. 9, Ediciones Historia, Lima.

BEIGEL, Fernanda (1998): "La 'nueva generación' en la praxis editorialista de José Carlos Mariátegui». En Simposio internacional Amauta y su época. Simposio internacional Amauta y su época: del 3 al 6 de setiembre de 1997, Minerva, Lima, pp. 61-87.

BIBLIOTECA NACIONAL DEL PERÚ (1919): Boletín de la Biblioteca Nacional. 5-6.

BUSTAMANTE Y BALLIVIÁN, Enrique (1924): «José María Eguren: Sus mejores poesías». Boletín Bibliográfico publicado por la Biblioteca de la Universidad de San Marcos, 1 (15), pp. 207-224.

EVOLUCIÓN, LA (1918): «La romería patriótica de Concepción». En La Evolución. Publicación diaria, Huancayo, 4 (590), p. 1. 
GOLDBERG, Isaac (1920): «José María Eguren». En Goldberg, Isaac. Studies in Spanish-Americam Culture. Brentano's, New York; pp. 296-306.

IFLA/UNESCO (1994): Manifiesto de la IFLA/UNESCO sobre la biblioteca pública. Accesible en Internet: http://www.ifla.org/VII/s8/unesco/ span.htm. Miércoles 21 de marzo, 13:50 horas.

LEGUÍA, Jorge Guillermo (1939): «Don Bartolomé Herrera». En Estudios Históricos. Ercilla, Santiago de Chile, pp. 63-100.

MARIÁTEGUI, José Carlos (1987) [1928]: «El proceso de la literatura». En Siete ensayos sobre la realidad peruana. Amauta, Lima; pp. 229-350.

NÚÑ̃Z, Estuardo, pról. (1961): Poesías Completas: José María Eguren, UNMSM. Patronato del Libro Universitario, Lima, pp. 9-31.

PRINCE, Carlos (1888-1889): Boletín Bibliográfico: Órgano de la imprenta y librería de Carlos Prince, № 1-24.

(1913): Mi estancia de medio siglo en Lima, 1862-1912. Impreso en la casa del Autor, Lima.

SÁNCHEZ, Luis Alberto (1922a): «Con el nuevo rector de San Marcos. El programa de reforma para la Universidad: La provisión de cátedras». Mundial, 3 (103): 2.

(1922b): «Las Reformas de San Marcos: Comentarios». Mundial, 3 (104): p. 2.

(1925): «Se nos ha ido un maestro». Mundial, 5 (243), p. 26.

(1987): Testimonio personal: Memorias de un peruano del siglo $X X$, t. 1, Mosca Azul, Lima.

TOVAR Y RAMÍREZ, Enrique Demetrio (1923): «Carlos Prince (18361919)». Boletín Bibliográfico publicado por la Biblioteca de la Universidad de San Marcos, 1(4), pp. 26-28.

UNMSM (1925): "Organización de servicios nocturno, dominical y feriado en la Biblioteca». Revista Universitaria, 19 (1): p. 305.

UNMSM-BIBLIOTECA (1923): «Crónica del Claustro: Conferencia sobre Pascal». Boletín Bibliográfico publicado por la Biblioteca de la Universidad de San Marcos, 1(2-3), p. 20.

(1924a): «Ecos: Los universitarios rusos emigrados». Boletín Bibliográfico publicado por la Biblioteca de la Universidad de San Marcos, 1(4), p. 30. 
(1924b): «Ecos: Las bibliotecas del Japón». Boletín Bibliográfico publicado por la Biblioteca de la Universidad de San Marcos, 1(7), p. 107.

(1925?): Recortes de periódicos. Biblioteca UNMSM, Lima.

(1940): «El catálogo por autores de la Biblioteca de San Marcos». Boletín Bibliográfico publicado por la Biblioteca de la Universidad de San Marcos, 10 (1-2), pp. 251-254.

VARELA ORBEGOSO, Luis (1925): «La Hora Actual: Pedro S. Zulen». Boletín Bibliográfico publicado por la Biblioteca de la Universidad de San Marcos, 2 (1), pp. 27-28.

VARIEDADES: REVISTA SEMANAL ILUSTRADA (1912): "Carta al señor C. C.», 8 (201): p. 24.

VILLARÁN, Manuel Vicente (1900): «Las profesiones liberales en el Perú». Anales Universitarios, 27, pp. 1-34.

VILLARREAL, Federico (1910): «Clasificación Decimal Bibliográfica». Revista de Ciencias, 13 (1), pp. 126-133.

VILLAVICENCIO, Víctor Modesto (1925): «El valor intelectual de Zulen». Boletín Bibliográfico publicado por la Biblioteca de la Universidad de San Marcos, 2 (1); pp. 6-9.

ZULEN, Esther (1925): «Bibliografía de Pedro Zulen». Boletín Bibliográfico publicado por la Biblioteca de la Universidad de San Marcos, 2 (1), pp. 9-19.

ZULEN, Pedro (1919). «Harvard y San Marcos». La Crónica (Lima), 20 de agosto de 1919, pp. 3-4. 